\title{
PARSING TURKISH USING THE LEXICAL FUNCTIONAL GRAMMAR FORMALISM ${ }^{1}$
}

\author{
Zelal Güingördii \\ Centre for Cognitive Science \\ University of Edinburgh \\ Edinburgh, Scotland, U.K \\ gungordu@cogsci.ed.ac.uk
}

\author{
Kemal Of lazer \\ Department of Computer Engineering \\ Bilkent University \\ Bilkent, Ankara, Turkey \\ ko@cs,bilkent.edu.tr
}

\begin{abstract}
This paper describes our work on parsing Turkish using the lexical-functional grammar formalism. This work represents the first effort for parsing Turkish. Our implementation is based on Tomita's parser developed at Carnegie-Mellon University Center for Machine Translation. The grammar covers a substantial subset of Turkish including simple and complex sentences, and deals with it reasonable amount of word order freeness. The complex agglutinative morphology of Turkish lexical structures is handled using a separate two-level morphological analyzer. After a discussion of key relevant issues regarding Turkish grammar, we discuss aspects of our system and present results from our implementation. Our initial results suggest that our system can parse about $82 \%$ of the sentences directly and almost all the remaining with very minor pre-editing.
\end{abstract}

\section{INTRODUCTION}

As part of our ongoing work on the development of computational resources for natural language processing in Turkish we have undertaken the development of a parser for Turkish using the lexical-functional grammar formalism, for use in a number of applications. This work represents the first approach to the computational analysis of Turkish, though there have been a number of studies of Turkish syntax from a linguistic perspective (e.g., [Meskill 1970]). Our implementation is based on Tomita's parser developed at Carnegie-Mellon University Center for Machine Translation [Musha et.al. 1988, Tomita 1987]. Our grammar covers a substantial subset of Turkish including simple and complex sentences, and deals with a reasonable amount of word order freeness.

Turkish has two characteristics that have to be taken into account: agglutinative morphology, and rather free word order with explicit case marking. We handle the rather complex agglutinative morphology of the Turkish lexical structures using a separate morphological processor based on the two-level paradigm [Evans 1990, Oflazer 1993] that we have integrated with the lexical-functional grammar parser. Word order freeness is dealt with by relaxing the order of phrases in the phrase structure parts of lexical-functional grammar rule by means of generalized phrases.

\footnotetext{
'This work was clone as a part of the first author's M.Sc. degree work at the Department of Computer Engineering of Bilkent University, Ankara, 06533 Turkey.
}

\section{LEXICAL-FUNCTIONAL GRAMMAR}

Lexical-functional grammar (LFG) is a linguistic theory which fits nicely into computational approaches that use unification [Shieber 1986]. A lexical-functional grammar assigns two levels of syntactic description to every sentence of a language: a constituent structure and a functional structure. Constituent structures (c-structures) characterize the phrase structure configurations as a conventional phrase structure tree, while surface grammatical functions such as subject, object, and adjuncts are represented in functional structure (f-structure). Because of space limitations we will not go into the details of the theory. One can refer to Kaplan and Bresnan [Kaplan and Bresnan 1982] for a thorough discussion of the LFG formalism.

\section{TURKISH SYNTAX}

In this section, we would like to highlight two of the relevant key issues in Turkish grammar, namely highly inflected agglutinative morphology and free word order, and give a description of the structural classification of Turkish sentences that we deal with.

\subsection{Morphology}

Turkish is an agglutinative language with word structures formed by productive affixations of derivational and inflectional suffixes to root words [Oflazer 1993]. This extensive use of suffixes causes morphological parsing of words to be rather complicated, and results in ambiguous lexical interpretations in many cases. For example:

(1) çocukları

a. child+PILU+3SG-POSS his children

b. child+3PL-POSS their child

c. child+PLU+3PL-POSS their children

d. child+PLU+ACC children (acc.)

Such ambiguity can sometimes be resolved at phrasc and sentence levels by the help of agreement requirements though this is not always possible:

$\begin{array}{lll}\text { Onlarm } & \text { çocukları } & \text { geldiler } \\ \text { it+PLU+GEN } & \text { child+PL.U } & \text { come+PAST } \\ & +3 \text { PL-POSS } & +3 P L \\ \text { (Their } & \text { children } & \text { came.) }\end{array}$


Table 1: Percentage of different word orders in 'Turkish.

\begin{tabular}{|c|c|c|}
\hline $\begin{array}{l}\text { Sentence } \\
\text { Type }\end{array}$ & $\begin{array}{l}\text { Childiren } \\
\text { Speech }\end{array}$ & $\begin{array}{l}\text { Adult } \\
\text { Speech }\end{array}$ \\
\hline SOV & $46 \%$ & $48 \%$ \\
\hline OSV & $7 \%$ & $8 \%$ \\
\hline SVO & $1 \% \%$ & $25 \%$ \\
\hline OVS & $20 \%$ & $13 \%$ \\
\hline VSO & $10 \%$ & $6 \%$ \\
\hline VOS & $0 \%$ & $0 \%$ \\
\hline
\end{tabular}

(2b) Cocukları child+PLU+3SG-POSS (His children child+PLUU+3PL-POSS

(Their children geldiler. came.) come+PAST+3PL came.) come+PASI'+3PL

For example, in (2a) only the interpretation (1c) (i.c., their children) is possible because:

- the agreement recjuirement between the modifict and the moditied parts in a possessive compound noun eliminates (la). ${ }^{2}$

- the facts that gel (come) does not subcategorize for an accusative marked direct object, and that in Turkish the subject of a sentence must be nominative ${ }^{3}$ elininate (Id).

- the agreement requirement between the stubject and the verb of a sentence eliminates ( $1 \mathrm{~b}$ ). ${ }^{4}$

In (2b), both (1a) and (1c) are possible (his children, and their children, respectively) because the modifier of the possessive compound noun is a covert one: it may be either onun (his) or onlarm (their). The other two interpretations are eliminated due to the same reasons as in (2a).

\subsection{Word Order}

If we concern ourselves with the typical order of constituents, Turkish can be characterized as being a stibjectobject-verb (SOV) language, though the dita in Table 1 from Irguvanl1 [Erguvanl1 1979], shows that other orders for constituents are also common (especially in discourse). In Turkish it is not the position, but the case of a noun phrase that determines its grammatical function in the sentence. Consequently typical order of the constituents may change rather freely without affecting the grammaticality of a sentence. Due to various syntactic and pragmatic constraints, sentences with the non-typical orders are not

\footnotetext{
${ }^{2}$ The agreement of the modifier must be the same as the possessive of the modified with the exception that if the modifier is third person plural the possessive of the modified may be third person singular.

${ }^{3}$ In 'Turkish, the nominative case is munnted

${ }^{4}$ In a Turkish sentence, person leatures of the subject and the verb should be the sime. This is true also for the number features with one exception: third person plural subjects may sometimes take third person singular verbs.
}

stylistic variants of the typicat versions which can be used interchangeably in any context [lirguvanli 1979]. For ex.ample, a constituent that is to be emphasized is generally placed immediately before the verb. This aflects the places of all the constituents in a sentence except that of the verb:

\begin{tabular}{|c|c|c|c|c|c|c|}
\hline (3a) & $\begin{array}{l}\text { IBen } \\
1 \\
(1 \text { gal }\end{array}$ & $\begin{array}{l}\text { cocu } \\
\text { child } \\
\text { the }\end{array}$ & a & $\begin{array}{l}\text { kital } \\
\text { book } \\
\text { tise } \\
\text { he chil }\end{array}$ & $\begin{array}{l}A C C \\
\text { i.) }\end{array}$ & $\begin{array}{l}\text { verdim. } \\
\text { give }+\mathrm{P}^{\prime} \mathrm{S} S \mathrm{~T}\end{array}$ \\
\hline$(3 b)$ & $\begin{array}{l}\text { Coct } \\
\text { child } \\
\text { (It w }\end{array}$ & DAT & $\begin{array}{l}\text { kital } \\
\text { book } \\
\text { lo gav }\end{array}$ & $A C C$ & $\begin{array}{l}\text { ben } \\
1 \\
\text { + } 15 \\
\text { ild the }\end{array}$ & $\begin{array}{l}\text { yerdim. } \\
\text { give+PAST }\end{array}$ \\
\hline$(3 c)$ & $\begin{array}{l}\text { Ren } \\
\text { I }\end{array}$ & $\begin{array}{l}\text { kital } \\
\text { book }\end{array}$ & $\mathrm{ACC}$ & $\begin{array}{l}\text { socu } \\
\text { child } \\
+ \text { ISO }\end{array}$ & $+1) \wedge \mathrm{T}$ & $\begin{array}{l}\text { verdim. } \\
\text { give+PAST }\end{array}$ \\
\hline
\end{tabular}

(3a) is an example of the typical word order whereas in (3b) the subject, ben, is emphatsized. Similarly, in (3c) llue indirect object, focuğa, is emphasized.

In acklition to these possible changes, the verb itsell mily move away from its typical place, i.e., the end of the sentence. Such sentences are called inverted sentencess and are typically used in informal prose and discourse.

However, this looseness of ordering constraints at sentence level does not extend into all syntactic levels. There are even constraints at sentence level:

- A nominative direct object should be placed immediately before the verto. ${ }^{5}$ Ifence, (5b) is angrammatical:

$$
\begin{aligned}
& \text { (5a) Ben cocuğa kitap verdim. } \\
& \text { I child+DAT book give+PAST+ISG } \\
& \text { (I give a book to the child.) } \\
& \text { (5b) *Gocuga kitap ben verdim. } \\
& \text { child+bAT book I give+PAST+1SG; }
\end{aligned}
$$

- Some adverbial complements of quality (those that are actually qualitative adjectives) always precede the verb or, if it exists, the indefinite direct object:

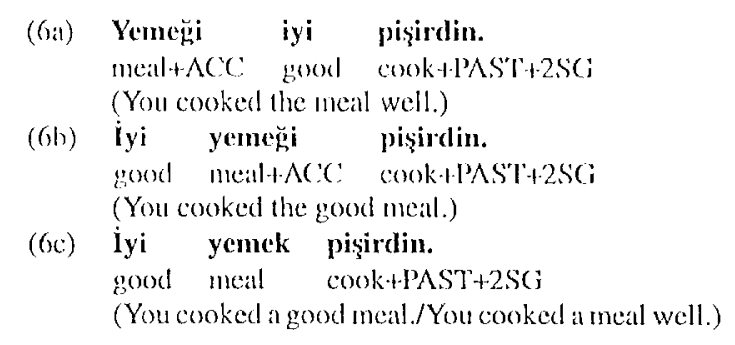

Note that althougl (6b) is grammatical $i y i$ is no more an alverbial complement, but is an adjective that modities yemegri. Note also that $(6 \mathrm{c})$ is ambiguous: iyi can be interpreted either as an adjective modifying yemek or as an

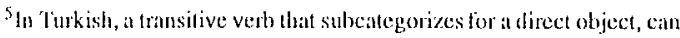
take either an accusillive marked or a nominative marked (unmanked on the surface) noun phase for that object. The function of alceusative case marking is to indicale that the object refers to a paticular definite contity, though there are very rate cases where his is not the case.

"Note that (3b,c) are grammatical since the theed object, kitabs, is minked aceusative.
} 
adverb modifying pisirdin.?

\subsection{Structural Classification of Sentences}

The following summarizes the major classes of sentences in Turkish.

-Simple Sentences: A simple sentence contains only one independent judgement. The sentences in (2), (3), (4a), (5a), and (6) are all examples of simple sentences.

-Complex Sentences : In Turkish, a sentence can be transformed into a construction with a verbal noun, a participle or a gerund by affixing certain suffixes to the verb of the sentence. Complex sentences are those that include such dependent (subordinate) clauses as their constituents, or as modifiers of their constituents. Dependent clauses may themselves contain other dependent clauses. So, we may have embedded structures such as:

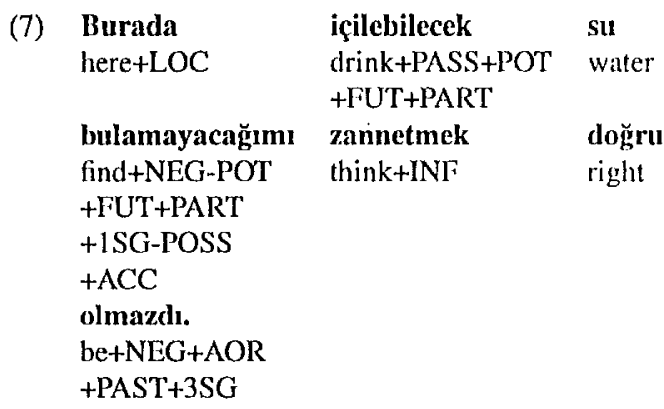

(It wouldn't have been right for me to think that I wouldn't be able to find drinkable water here.)

The subject of (7) (burada içilebilecek su bulamayacağımı zannetmek - to think that I wouldn't be able to find drinkable water here) is a nominal dependent clause whose definite object (burada işilebilecek su bulamayacağımı that I wouldn't be able to find drinkable water here) is an adjectival dependent clause which acts as a nominal one. The indefinite object of this definite object (içilebilecek su - drinkable water) is a compound noun whose modifier part is another adjectival dependent clause (icilebilecek drinkable), and modified part is a noun (su-water).

It should be noted that there are other types of sentences in the classification according to structure. However, we will not be concerned with them here because of space limitations. (See Şimşek [Şimsek 1987], and Güngördii [Güngördü 1993] for details.)

\section{SYSTEM ARCHITECTURE AND IM- PLEMENTATION}

We have implemented our parser in the grammar development environment of the Generalized LR Parser/Compiler developed at Carnegie Mellon University Center for Machine Translation. No attempt has been made to include

\footnotetext{
${ }^{7}$ The second interpretation is possible since yemek is an indefinite direct object.
}

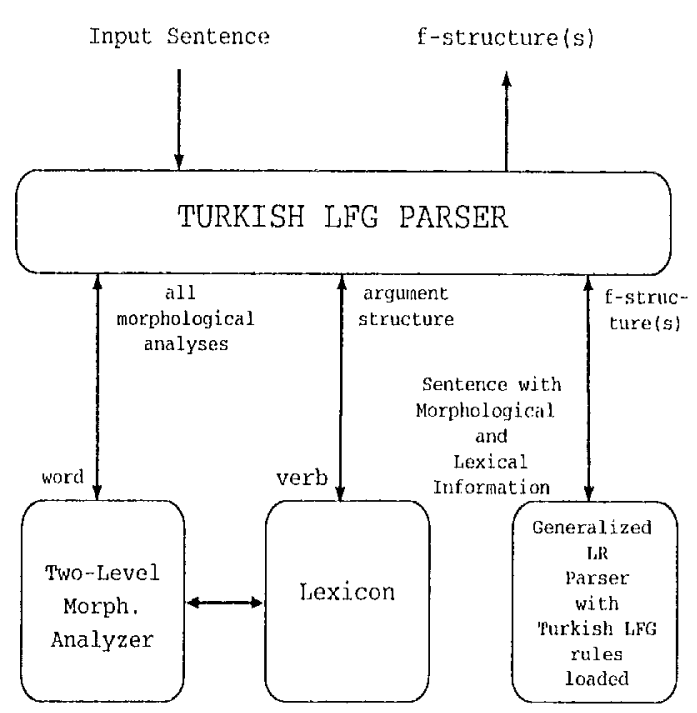

Figure 1: The system architecture.

morphological rules as the parser lets us incorporate our own morphological analyzer for which we use a full scale two-level specification of Turkish morphology based on a lexicon of about 24,000 root words[Oflazer 1993]. This lexicon is mainly used for morphological analysis and has limited additional syntactic and semantic information, and is augmented with an argument structure database.

Figure 1 shows the architecture of our system. When a sentence is given as input to the program, the program first calls the morphological analyzer for each word in the sentence, and keeps the results of these calls in a list to be used later by the parser." If the morphological analyzer fails to return a structure for a word for any reason (e.g., the lexicon may lack the word or the word may be misspelled), the program returns with an error message. After the morphological analysis is completed, the parser is invoked to check whether the sentence is grammatical. The parser performs bottom-up parsing. During this analysis, whenever it consumes a new word from the sentence, it picks up the morphological structure of this word from the list. If the worl is a finite verb or an infinitival, the parser is also provided with the subcategorization lrame of the word. At the end of the inalysis, if the sentence is grammatical, its i-structure is output by the parser.

\footnotetext{
${ }^{\text {X} T h e ~ m o r p h o l o g i c a l ~ a m a l y z e r ~ r e t u r n s ~ a ~ l i s t ~ o f ~ f e a t u r e-v a l u e ~ p a i r s . ~ F o r ~}$ instance for the word evdekilerin (of those (things) in the house/your things in the house) it will return

1. $\left(\left({ }^{*} \mathrm{CAT} * \mathrm{~N}\right)\left({ }^{*} \mathrm{R}^{*} " \mathrm{eV} "\right)\left({ }^{*} \mathrm{CASE}{ }^{*}\right.\right.$ LOC $)\left({ }^{*} \mathrm{CONV}{ }^{*} \mathrm{ADJ}\right.$ "ki.) (*AGR* 3PL) (*CASE* GEN))

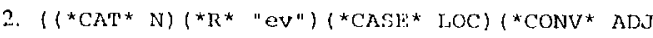
"k.i.")(*AGR* 3PL) (*POSS* 2SG))

${ }^{9}$ Recall thit there may be a number of morphologically ambiguous interpretations of a word. In such a case, the morphological analyzer returns all of the possible morphological structures in a list, and the parser takes care of the ambiguity regatding the grammar rules.
} 
Table 2: The number of rules for each cattegory in the grammar.

\begin{tabular}{|l|c|}
\hline \multicolumn{1}{|c|}{ Category } & Number of Rules \\
\hline Noun phrases & 17 \\
Adjectival phrases & 10 \\
Postpositional phrases & 24 \\
Adverbial constructs & 50 \\
Verb phrases & 21 \\
Dependent clauses & 14 \\
Sentences & 6 \\
Lexical look up rules & 11 \\
\hline TOTAL & 153 \\
\hline
\end{tabular}

\section{TIIE GRAMMAR}

In this section, we present an overview of the LICG specification that we have developed for Turkish syntax. Our grammar includes rules for sentences, dependent clatuses, noun phrases, adjectival phrases, postpositional phrases, adverbial constructs, verb plerases, and a number of lexical look up rules. ${ }^{10}$ Table 2 presents the number of rules for each category in the granmar. There are also some intermediary rules, not shown here.

Recall that the typical order of constituents in a sentence may change due to a number of reasons. Since the order of phrases is fixed in the phrase structure component of an LFC rule, this rather free nature of word order in sentence level constitutes a major problem. In order to keep from using a number of redundant rules we adopt the following strategy in our rules: We use the same place holder, $\langle\mathrm{XP}\rangle$, for all the syntactic categories in the phrase structure component of a sentence or a dependent clatuse rule, and check the categories of these phrases in the equations part of the rule. In Figure 2, we give a grammar rule for the sentence with two constituents, with an informal description of the equation part. $^{11}$

Recall also that an indefinite object should be placed immediately before the verb, and some adverbial complements of quality (those that are actually gualitative adjectives) always precede the verb or, if it exists, the indefinite direct object. In our grammar, we treat such objects and ad verbial complements as parts of the verb phrase. So, we do not check these constraints at the sentence or dependent clause level.

\section{PERTORMANCE EVALUATION}

In this section, we present some results about the performance of our system on test runs with four different texts on different topics. All of the texts are articles taken from magazines. We used the CMU Common Lisp system running

\footnotetext{
10 Recall that no morphological rules ate included. The lexical look up rules are used just to call the morphologicul analyzer.

"Note that $x 0, x$, and $x 2$ refer to the functional strucures of the selltence, the first constituent and the second constituent in the phatse structure, respectively.
}

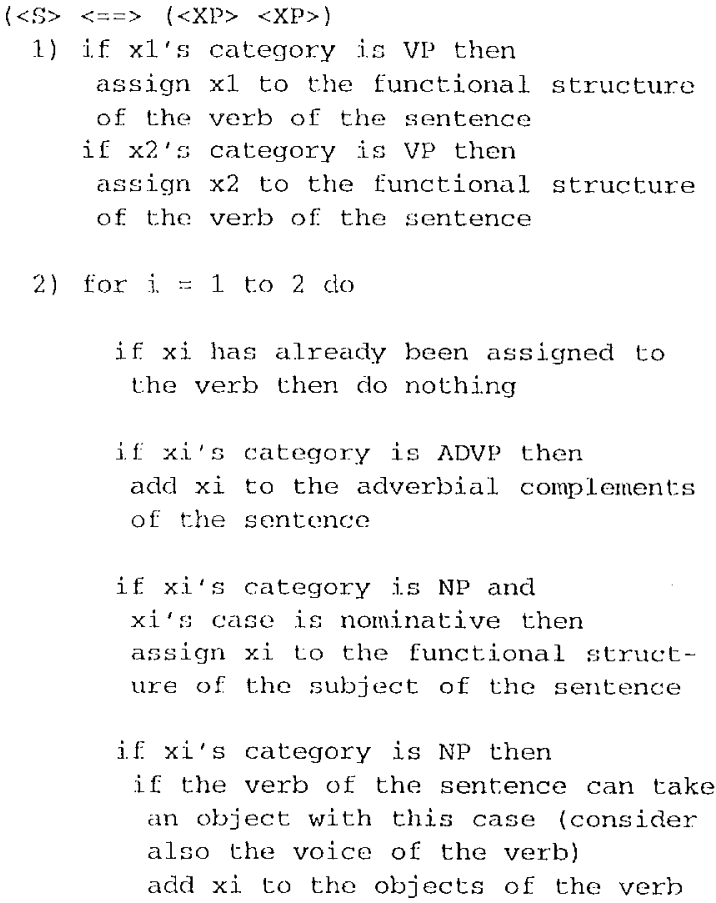

3) check if the verb has taken all the objects that it hás to take

4) make sure that the verb has not taken more than one object with the same thematic role

5) check if the subject and the verb agree in number and person: if the subject is defined (overt) then

if the agrement feature of the subject is thind person plural

then the agreement feature of the verb may be either third person singular: or third person plural else

the agreement features of the subject and the verb must be the same

else if the subject is underined (covert) then assign the agreement feature of the verb to that of the subject

ligure 2: An LFG rule for the sentence level given with an informal description of the equation part. 
Table 3: Statistical information about the test runs.

\begin{tabular}{|c|c|c|c|c|c|c|}
\hline Doc & \#S & $\begin{array}{c}\# S \\
\text { in } \\
\text { Scope }\end{array}$ & $\begin{array}{c}\# S \\
\text { ign. }\end{array}$ & $\begin{array}{c}\text { \#S } \\
\text { after } \\
\text { Pre-ed. }\end{array}$ & $\begin{array}{c}\text { \#P } \\
\text { per } \\
\text { Sent. }\end{array}$ & $\begin{array}{c}\text { Secs } \\
\text { per } \\
\text { Sent. }\end{array}$ \\
\hline \hline 1 & 43 & 30 & 0 & 55 & 4.28 & 12.26 \\
2 & 51 & 41 & 2 & 62 & 5.02 & 8.92 \\
3 & 56 & 48 & 1 & 64 & 4.87 & 10.28 \\
4 & 80 & 70 & 0 & 97 & 3.25 & 7.46 \\
\hline Tot. & 230 & 189 & 3 & 279 & - & - \\
\hline & $100 \%$ & $82 \%$ & & & & \\
\hline
\end{tabular}

\#S: Number of sentences, \#P: Number of parses.

in a Unix environment, on SUN Sparcstations at Center for Cognitive Science, University of Edinburgh. ${ }^{12}$

In all of the texts there were some sentences outside our scope. These were:

- sentences that contain finite sentences as their constituents or modifiers of their constituents,

- conditional sentences,

- finite sentences that are connected by coordinators (and/or), and

- sentences with discontinuous constituents. ${ }^{13}$

We pre-edited the texts so that the sentences were in our scope (e.g., separated finite sentences connected by coordinators and parsed them as independent sentences, and ignored the conditional sentences). Table 3 presents some statistical information about the test runs. The first, second and third columns show the document number, the total number of sentences and the number of sentences that we could parse without pre-editing, respectively. The other columns show the number of sentences that we totally ignored, the number of sentences in the pre-edited versions of the documents, average number of parses per sentence gencrated and average CPU time for each of the sentences in the texts, respectively. It can be seen that our grammar can successfully deal with about $82 \%$ of the sentences that we have experimented with, with almost all remaining sentences becoming parsable atter a minor pre-editing. This indicates that our grammar coverage is reasonably satisfactory.

Below, we present the output for a sentence which shows very nicely where the structural ambiguity comes out in Turkish. ${ }^{14}$ The output for (8a) indicates that there are four

\footnotetext{
${ }^{12}$ We should however note that the times reported are exclusive of the time taken by the morphological processor, which with a 24,000 word root Jexicon is rather slow and can process about 2-3 lexical forms per second. We have, however, ported our morphological analyzer to the XEROX TWOL system developed by Kartunen and Beesley [Karttunen and Beesley 1992] and this system can process about 500 forms a second. We intend to integrate this to our system soon.

${ }^{13}$ Word order freeness in 'lurkish allows various kinds of discontinuous constituents, e.g., an adverbial adjunct cutting in the middle of a compound noun.

${ }^{14}$ This example is not in any of the texts mentioned above. It is taken from the first author's thesis [Giingördii 1993].
}

ambiguous interpretations for this sentence as indicated in $(8 \mathrm{~b}-\mathrm{e}):^{15}$

$\begin{array}{lllll}\text { (8a) Küçiik } & \text { kırmu } & \text { top } & \text { gittikçe } & \text { hrzlandl. } \\ \text { little } & \text { red } & \text { ball } & \text { go+GER } & \text { speed up } \\ & \text { red paint+ } & & \text { gradually } & + \text { PAST } \\ & \text { 3SG-POSS } & & & +3 S G\end{array}$

(8b) The little red ball gradually sped up.

(8c) The little red (one) sped up as the ball went.

(8d) The little (one) sped up as the red ball went.

(8e) It sped up as the little red ball went.

The output of the parser for the first interpretation is given in Figure 3. This output indicates that the subject of the sentence is a noun phrase whose modifier part is kiigsik, and modified part is another noun phrase whose modifier part is kurmizi and modified part is top. The agreement of the subject is third person singular, case is nominative, etc. Hizland is the verb of the sentence, and its voice is active, tense is past, agreement is third person singular, etc. Gittikģe is a temporal adverbial complement.

Figures 4 through 7 illustrate the c-structures of the four ambiguous interpretations (8b-e), respectively: ${ }^{16}$

- In (8b), the adjective kırmizt modifies the noun top, and this noun phrase is then modified by the adjective kiiçuik. The entire noun phrase functions as the subject of the main verb hizland, and the gerund gittikge functions as an adverbial adjunct of the main verb.

- In (8c), the adjective kırmuzı is used as a noun, and is modified by the adjective küçïk. ${ }^{17}$ This noun phrase functions as the subject of the main verb. The noun top functions as the subject of the gerund gittikse, and this non-finite clause functions as an adverbial adjunct of the mian verb.

- In (8d), the adjective kiigriok is used as a noun, and functions as the subject of the main verb. The noun phrase kirmizi top functions as the subject of the gerund gittikge, and this non-finite clause functions as an adverbial adjunct of the main verb.

- In (8e), the noun phrase kïsiik krrmzr top liunctions as the subject of the gerund giltikge (ct. (8b) where it functions as the subject of the main verb), and this non-finite clause functions as an adverbial adjunct of the main verb. Note that the subject of the main verb in this interpretation (i.e., it) is al covert one. Hence, it does not appear in the c-structure shown in Figure 7.

\footnotetext{
${ }^{15}$ In fict, this sentence has a fifth interpretation due to the lexical ambiguity of the second word. In flurkish, krrmz is the name of at shining, red paint obtained from an insect with the same nane. So, (8a) also means " $/ /$ in little red paint sped up as the hall went.' However, this is very unlikely to come to mind even for native sperkers.

If'The e-struetures given here are simplified by removing some nodes introduced by certain intermediary rules to increase readability.

${ }^{17}$ In Turkish, any adjective can be used as a noun.
} 


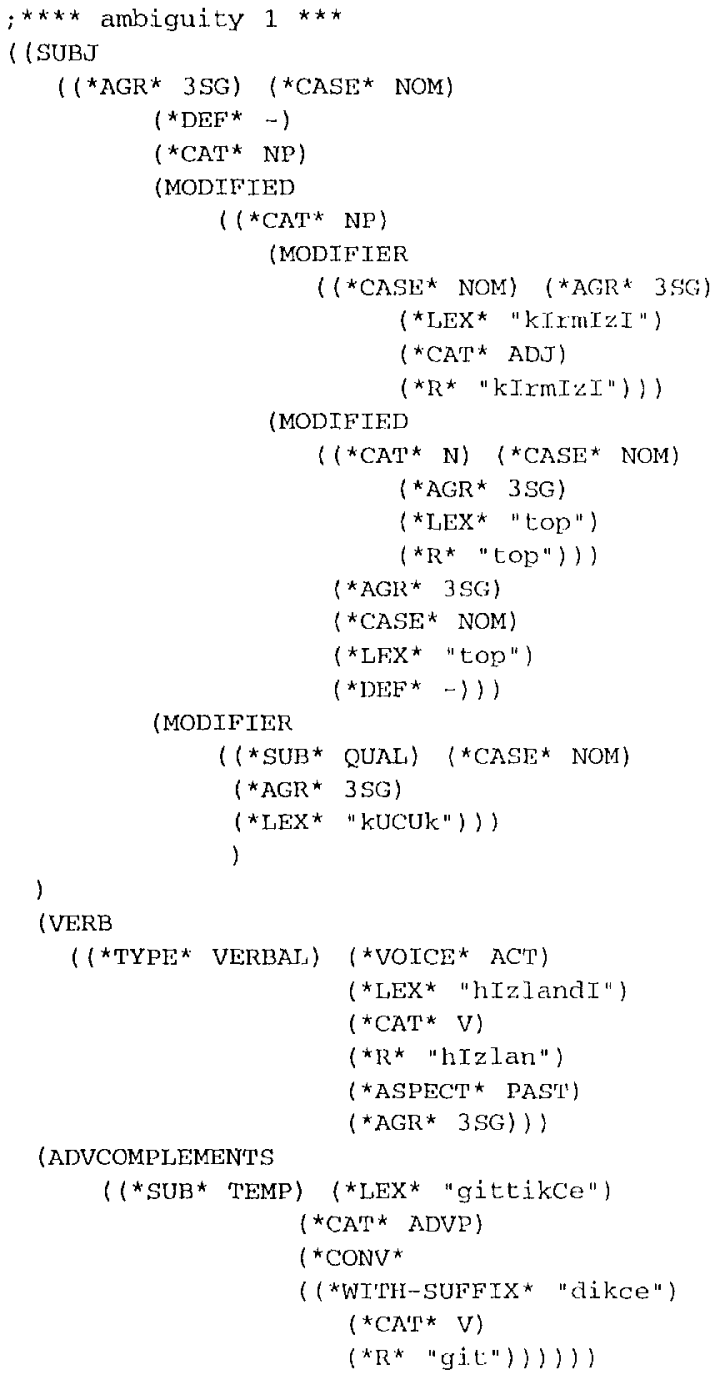

Figure 3: Output of the parser for the first the anbigtous interpretation of (8a) (i.e., (8b)).

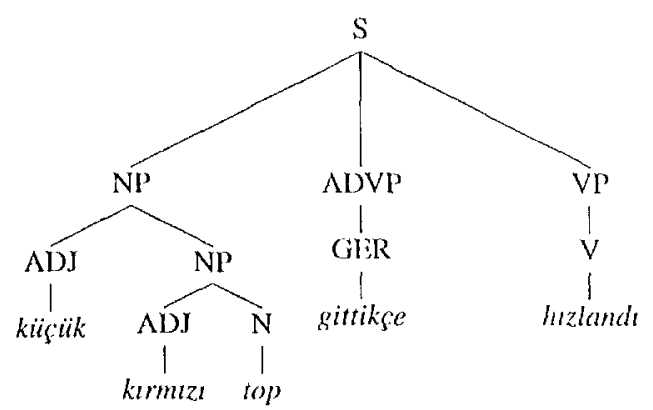

Figure 4: C-structure for (8b).

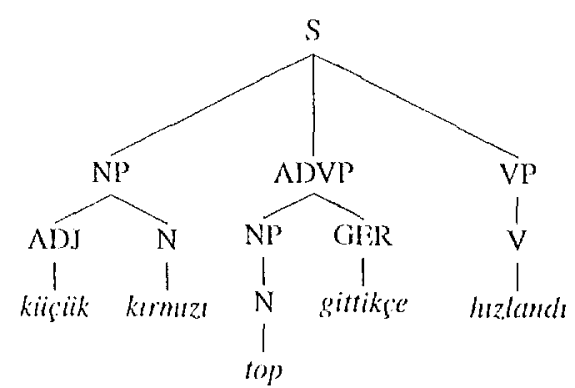

Figure 5: C-structure for (8c).

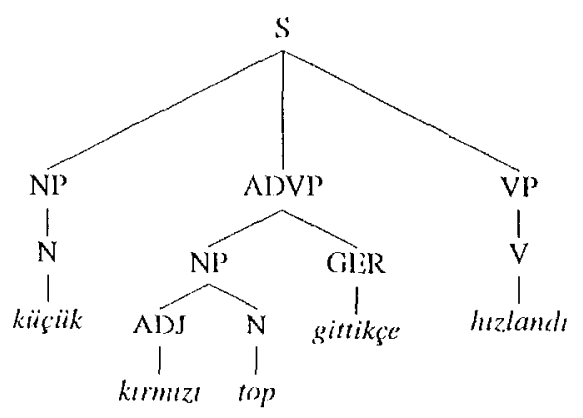

Iigure 6: C-structure for (8d).

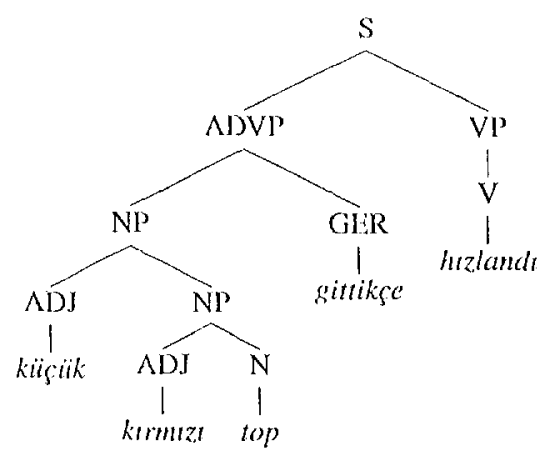

Figure 7: C-structure for (8e). 


\section{CONCLUSIONS AND SUGGESTIONS}

We have presented a summary and highlights of our current work on providing an LFG specification for Turkish syntax. To the best of our knowledge this is the first such effort for constructing a computational grammar for Turkish. Our domain includes structurally simple and complex Turkish sentences. The rather complex morphological analyses of agglutinative words structures of Turkish are handled by a full-scale two-level morphological specification implemented in PC-KIMMO.

We have number of directions for improving our grammilr and parser:

- Turkish is very rich in terms of adverbial constructs. We handle a great deal of these constructs by using a large number of rules. We are now in the process of developing a tagger with a multi-word construct recognizer to preprocess the text so that many multi-word and idiomatic constructs can be handled outside the grammar. In this way, multi-word constructs such as yapar yapmaz (do+AOR+3SG do+NEG+AOR+3SG) (as' soon as (one) does (that)) where both lexical categories are verbal but the compound construct is an adverb, can be handled, so can idiomatic constructs like yam stra (side+3SG-POSS row) (besides) where the function and semantics of the multi-word construct has nothing to do with the function and semantics of the constituent lexical forms.

- We are currently working on extending the subset of sentences dealt with in respect of structure.

- We are currently working on augmenting our lexicon with substantial lexical information and selectional restriction information to be used with an integrated ontological database.

\section{ACKNOWLEDGEMENTS}

We would like to thank Carnegie-Mellon University, Center for Machine Translation for making available to us their LFG parsing system. We would also like to thank Elistbet Engdahl and Matt Crocker of the Centre for Cognitive Science, University of Edinburgh, for providing valuable comments and suggestions. This work was done as a part of a large scale NLP project (TU-LANGUAGE) which is funded by a NATO Grant under the Science for Stability Program.

\section{References}

[Antworth 1990] E. L. Antworth, PC-KIMMO: A Twolevel Processor for Morphological Analysis. Summer Institute of Linguistics, 1990.

[Erguvanl, 1979] E. E. Erguvanh,. The Function of Word Order in Turkish Grammar. PhD thesis, Department of Linguistics, University of California, Los Angeles, 1979.
[Güngördï 1993] Z. Güngördii,, "A lexical-functional grammar for Turkish," M.Sc, thesis, Department of Computer lingineering and Information Sciences, Bilkent University, Ankara, Turkey, July 1993.

[Kaplan and Bresnan 1982] R. Kaplan and J. Bresnan, The Mental Representation of Grammatical Relations, chapter Lexical-Functional Grammar: A Formal System for Grammatical Representation, pp. 173-281. MIT Press, 1982.

[Karttunen and Beesley 1992] L. Karttunen and K. R. Beesley,. "Two-level rule compiler,". Technical Report, XISROX Palo Alto Research Center, 1992.

[Meskill 1970] R. H. Meskill, A TransformationalAnalysis of Turkish Syntax. Mouton, The Hague, Paris, 1970.

[Musha et.al. 19881 H. Musha T. Mitamera and M. Kee,. The Generalized LR Parser/Compiler Version 8.1: User's Guide. Carnegie-Mellon Univessity - Center for Machine Translation, April 1988.

[Oflazer 1993] K. Ollazer, "Two-level description of Turkish morphology," in Proceedings" of the Sixth Conference of the European Chapter of the Association for Computational Linguistics, April 1993. $\Lambda$ full version is to appear in Literary and Linguistic Computing, Vol.9 No.2, 1994.

[Shicber 1986] S.M. Shieber, An Introduction to Unification-Based Approaches to Grammar. CSLI-Lecture Notes 4, 1986.

[Şimsek 1987] R. Şimşek, Örneklerle Tïrķ̧e Sözdizimi (Turkish Syntax with Examples). Kuzey Matbaacilik, 1987.

[Tomita 1987] M. Tomita, "An elficient augmentedcontext-fiee parsing algorithm," Computational linguistics, vol. 13, 1-2, pp. 31-46, January-June 1987. 